Mr. Harrington, Ann Arbor-

Will do as Greenwich does.

Prof. HOLDEN, Washburn ObservatoryBegin in 1890.

Prof. Young, PrincetonBegin January I, I88,5.

Mr. SwifT, Warner Observatory-Begin January $\mathbf{r}, \mathbf{1} 885$.

Prof. LANGLey, AlleghanyBegin January I, I885.

Mr. PORTER, CincinnatiBegin January I, 1885 .

Prof. PRITCHeTT, Washington University ObservatoryWait a year at least for general concensus.

Prof. Peters, Clinton. We extract his letter :-

"I have, from the beginning, attached very little importance to the object and the proceedings of the International Meridian Conference.

"The suggestions and recommendations which have been the result refer principally to things that are already in existence for example, the reckoning of geographical longitudes east and west from Greenwich is in practice with most nations. The proposition to count the hours of the day from o to 24 also in civil life will scarcely ever be adopted, for nobody (except perhaps sick people lying in bed) will have patience enough to count the striking of the clock up to 24 , not to speak of the greater liability of miscounting the strokes and of the difficulty in reading off the turret dial if the circle be divided into twentyfour parts. But what concerns astronomers directly is the change proposed by the Conference in the beginning of the astronomical day, in regard to the introduction of which you ask for my views. It is quite unimportant, of course, whether we begin from noon or from the preceding midnight; the reasons for taking the former as the starting-point exist no longer. Our clocks nowadays are not regulated, as in former times, by observing the culmination of the sun, and with the telescopes of increased size observations are continued not during the night alone, but are carried on as well in day-time, so that a break in the date at midnight is hardy more grievous than one at noon. While thus we might readily conform with the proposal of the Conference, and put our clocks back by twelve hours, we ought to hesitate nevertheless very much to do so at once, especially for two reasons: First, a general agreement and understanding among astronomers (not of the United States alone but of all nations) should be had; otherwise it would become necessary for avoiding confusion to add to every observation we publish some such words as 'old-style time' or 'new-style time.' The subject undoubtedly will be discussed in the astronomical periodicals, and in societies representing our science. If authorities such as the Royal Astronomical Society, the German Astronomical Gesellschaft, the larger active observatories, \&c., agree in favour of the change, the system of reckoning the astronomical day from midnight will soon be adopted universally. But a partial proceeding seems highly objectionable. Second, if we make a change in the time-keepers: of the Observatory now, the use of the astronomical ephemerides, as they lie com puted before us, will be made in many respects heavy. 'Take, for example, the places of the fixed stars, which are given for upper culmination from ten to ten days. When the sidereal day begins before noon, its date in the new arrangement of the solar day is changed. And every star place that we wish to take ont of the ephemeris, therefore, requires some additional attention and reflection as to the corresponding date. In the American Nautical Almanac, where the tenths of the solar day are given, this inconvenience, to be sure, is not so great; we need only to diminish our argument by 0.5 day for having that of the table. A similar reduction of the argument must be made in using the lunar ephemeris, and of course in all the data expressed in solar time. In this way a source for at least possible mistakes is opened, and I think it therefore desirable that the change in the Nautical Almanacs should precede that in the observatories. The American as well as the British Nautical Almanacs are published as far as 1887 , inclusive; the next or the next two following years may be under preparation.

"These considerations together lead me to the conclusion that it seems not advisable to introduce the change in the beginning of the astronomical day before the year 1890 ."

More recently two European astronomers have recorded their opinions. Prof. Struve in a pamphlet, ${ }^{1}$ and Prof. Oppolzer in the Monthly Notices. The former thus expresses his views :-

"In regard to the change in the beginning of the astronomical day, thinks that the question before astronomers is not only of giving up a long-established custom, with consequent changes of rules of many years' standing, but it also involves a serious interruption of astronomical chronology. Without a doubt the astronomer would have to make a decided sacrifice in conforming to the wish of the Conference; but, after all, this sacrifice is no greater than our forefathers made when they changed from the Julian to the Gregorian calendar-a sacrifice to convenience of which we are still made sensible whenever we have occasion to go back to early observations.

"We need have little hesitation in making a similar sacrifice if it will prevent discordance between the civil and scientific custom of reckoning time, particularly troublesome where astronomical establishments come in contact with the outer world.

"Prof. Struve states that the Pulkowa Observatory is prepared to adopt the new time, the only question being as to the epoch when the change should be introduced in the publications of the Observatory. He is inclined to recommend that this should be deferred until some arreement can be reached by astronomers, and until the new time is adopted in the Ephemerides. This might be for the year I890, or perhaps, better still, at the beginning of the next century."

Prof. Oppolzer's opinion is as follows:-

"When once such a universal time is introduced for all purposes it is quite natural that the question must arise, if there is indeed so great a necessity to retain in astronomy, and only in astronomy, a different reckoning of time. I fail to see this necessity, and I do not think that it would cause any serious trouble or confusion if a change were to be made in our astronomical reckoning; whilst a special mode of reckoning time in one science only, when all others use the generally-adopted standard, will, without doubt, be a source of error and confusion.' He then takes up in some detail the objections urged against the proposed change by Prof. Newcomb, and he discusses the changes which would be necessary in the Ephemerides. Prof. Oppolzer proposes to give practical effect to his views by adopting the new reckoning of time in an ex. tensive list of 8000 solar and 5200 lunar eclipses which he is now preparing for publication."

Science, in an article on this subject, concludes as follows :-

"It is difficult to see how this matter will finally be decided. It is evidently a question for astronomers to settle among themselves; but so far they seem to be very evenly divided. For instance : out of some twenty-seven astronomers whose opinions, more or less decided, have been accessible for a count, thirteen seem inclined to favour the proposed. change, while fourteen are opposed to it. And among the pros are Adams, Struve, and Christie ; among the cons, Newcomb, Foerster, and Auwere."

\section{MR. FREDERICK SIEMENS'S GAS LAMP}

THE illuminating power of the most novel appliances for the production of light having, for economical reasons, been made more and more intense, and therefore more injurious to the eyesight, it follows that the eye must be protected as much as possible from the direct action of the light, with the least possible loss or diminution of effect. In other words, rooms should be lighted only by means of indirect rays or diffused light, the source of light itself not being directly visible. This is, in the author's opinion, a consideration of the highest importance as regards artificial illumination, which has only as yet received partial attention.

Until lately three main points only have been considered in any lighting application-viz. that the apparatus employed should be simple both in its construction and in its use : that the light should be of sufficient intensity for 
the purposes required; and that the first cost and the maintenance of the plant employed should be very moderate. In public estimation, simplicity is the first desideratum; and hence a simple and direct form of illumination has always been preferred to a more complicated arrangement, even when the latter has been found more economical as regards first cost and maintenance, and more brilliant in its effects. At the present time, however, in addition to these requirements, a purer atmosphere and a more pleasant temperature in our apartments are desired, which matters received very little or no attention in former days, when people were content with a simple dim light, and took little interest in sanitary matters. The regenerative gas-burner may be regarded as a combined lighting and ventilating apparatus, by the employment of which the close oppressive atmosphere, so unpleasant at large gatherings, may be entirely avoided. In fact, it is the outcome of the demand for cooler and purer air in our apartments, combined with light of high intensity.

The lamp has been designed with a view to protect the eyesight from the direct action of the source of light, without diminishing its power; its construction will be understood from the following description:-Four hoods, $1,2,3,4$, of sheet iron or other suitable material, are arranged within one another in such a manner that the products of combustion travel downward between

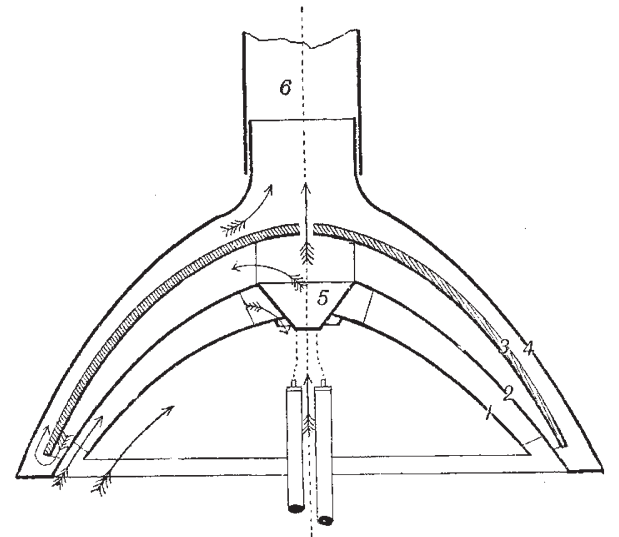

2 and 3 , and upward between 3 and 4 , while the air to be heated for feeding the flame passes upward between I and 2. On the uppermost hood, 4, a chimney, 6, is provided, while the hood, 3 , is shortened below so as to allow a clear passage for the products of combustion from the space between 2 and 3 , to that between 3 and 4 , and thus to the chimney. The hood, 2, carries at its apex an inwardly projecting outlet, 5 , through which the products of combustion pass away as described, first downwards and then upwards, through the passages between the three upper hoods, into the chimney. The lowest or innermost hood, $\mathrm{r}$, is open, so that the air may pass upwards between the hoods, I and 2 , as indicated by the arrows, to fill the inner space of the hood with heated air. The inner surface of this hood acts as a reflector, and in its focus are placed one or more fishtail burners of the usual type. As soon as the hood, 2 , becomes sufficiently heated, through the action of the products of combustion passing between it and 3 , the air between $\mathrm{I}$ and 2 will become heated, and, diminishing in its specific gravity, will automatically rise and fill the upper portion of the cone inside the hood, $r$. By this arrangement the gas-jets burn within an atmosphere of heated air, with which they are consequently permanently supplied; the temperature of the air increasing with that of the gas-flames, and the brilliancy of the light increasing in the same ratio. The action is perfectly automatic, for, as the products of combustion pass away through the chimney 6 , fresh heated air comes in at the same rate into the inner space of the hood I containing the gasflames, to occupy the space which would otherwise be filled with cold air from the atmosphere below. The hot air which is supplied from the column of heated air formed between the hoods 1 and 2 will, on account of its lower specific gravity, always fill the upper space inside the hood I, thus preventing the cold air of the atmosphere, which is at least three times as heavy, from rising inside the hood, I, above a certain level, even in case of a disturbance in the atmosphere of the room. Thus no glass partition to exclude the cold air is required. The flame reflects its light directly downwards, as also from the inner surface of the hood, there being consequently an entire absence of shadows.

The light can be more or less concentrated or diffused, as desired, by varying the shape of the hood or reflector used. In some cases, where it is required to diffuse the light widely, or to diminish the downward radiation of heat, a bell-shaped glass, with its apex upwards, and its surface curving parabolically in the downward direction, may be employed, so as to cause all the rays of light it receives either to be refracted or to be reflected horizontally. If it is only desired to reduce the intensity of the downward radiation of heat, clear glass should be employed; if, however, it is also desired to diffuse the light, opaque glass is requisite, and the light may be thus more or less diffused, as may be required. The glass bell is suspended on a wire net of large mesh attached to a metal ring below, upon which and upon the netting the glass rests, so that, in case of accident, the broken glass would not fall below. It allows of free access to the flame, and does not form an integral part of the apparatus, so that its employment will not cause any particular trouble or inconvenience. As the intensity of the light depends entirely upon the up-current of heated air, the hoods may have any shape most suitable for the reflector and for the purpose of diffusing the light, provided that the height of the column of hot air between the hoods I and 2 be not relatively diminished.

The following tests of this lamp have been made :-The burners or jets removed from the dome were tested with the rays horizontal. The consumption of gas was 20 cubic feet per hour, and the illuminating power $57^{\circ} 5$ candles, or 2.875 candles per cubic foot. They were then placed at an elevation of I foot 6 inches perpendicularly over a plain glass mirror placed at an angle of $45^{\circ}$, and in a line with the disk of the photometer. The distance from the standard light to the glass reflector was i 8 feet 6 inches, which, added to the $I$ foot 6 inches that the burners were placed above the reflector, made together 20 feet, the distance at which the light to be tested has to be fixed from the standard light in the photometer employed. In this case the consumption was again 20 cubic feet per hour, and the illuminating power was found to be 55 candles, or 275 candles per cubic foot; so that it would appear that there is an absorption by the glass in reflection of 4.35 per cent. The burners having been fixed in the dome reflector, the lamp, thus arranged, was tested again as in the last experiment. The consumption of gas was $20^{\circ} 5$ cubic feet per hour, and the illuminating power $62^{\circ} 5$ candles, or: an average of $3^{\circ} 048$ candles per cubic foot of gas, or 3.180 candles per cubic foot if the 435 per cent. found to be absorbed by the glass are added. The difference between 2.875 and 3.180 candles, or 0.305 candle, per cubic foot gives the increase of light due to the use of the reflecting cone. After burning for some time the lamp was again tested, the consumption of gas was found to be reduced to $15 \% 5$ cubic feet per hour, and the illuminating power to be increased to I I 5 candles, being an average of 7.42 candles per cubic fout; or, allowing for loss by absorption, 774 candles per cubic foot. The difference between this and 3.180 candles, 
or 4.560 candles, gives the gain in light per cubic foot of gas due to the regenerative arrangement, the gas burning within a highly-heated atmosphere.

\begin{tabular}{|c|c|c|c|c|c|c|}
\hline Date. & $\begin{array}{l}\text { Particulars of } \\
\text { Burners. }\end{array}$ & 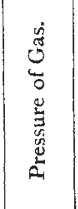 & 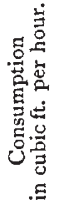 & 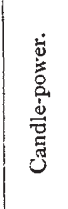 & 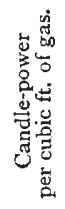 & 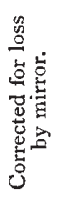 \\
\hline May 6, r885. & $\begin{array}{l}\text { Gas jets taken :out of } \\
\text { lamp } \\
\text { Same jets raised I8 inches } \\
\text { to reflect light on } \\
\text { mirror }{ }^{*} \text {. } \\
\text { Same jets burning in cold } \\
\text { lamp jets burning in hot } \\
\text { Same je. }\end{array}$ & $\begin{array}{c}\text { Ten- } \\
\text { tenths }\end{array}$ & $\begin{array}{l}20^{\circ} 0 \\
20^{\circ} \circ \\
20^{\circ} 5 \\
15{ }^{\circ} 5\end{array}$ & $\begin{array}{l}57^{\circ} 5 \\
55^{\circ} \circ \\
62^{\circ} 5 \\
115^{\circ} \circ\end{array}$ & $\begin{array}{l}2^{\circ} 75^{\circ} \\
3^{\circ} 04^{8} \\
7^{\circ} 4^{20}\end{array}$ & $\begin{array}{c}\cdots \\
\cdots \\
3 \cdot 180 \\
7 \cdot 740\end{array}$ \\
\hline
\end{tabular}

Of course light may be diffused or transmitted indirectly by other means than those described, though not perhaps in a more simple or economical way. The electric light has been to a certain extent already treated in a similar way by suspending arc lights at great altitudes, and by means of reflectors concentrating the light down upon certain areas. The intention has been, by this means, to illuminate whole towns or districts of towns from single sources of light. This can, in the author's opinion, be done if the concentration of the light is effected in a different way from what has been hitherto attemptedviz., by the employment of very much larger reflectors. In this way the loss of light sideways and the deep shadows that have been produced will be avoided. It matters very little at what height the light is placed, the chief question being what area has to be illuminated; and then the form of reflector suitable for the purpose can be easily determined upon.

In conclusion, it must be remembered that illumination from above downwards is in nearly all cases the preferable mode of distributing light, as Nature herself proves in having one light only, the sky being the diffusing agent by which the most perfect distribution of light is effected. Nature possesses, indeed, a gigantic reflector in the at mosphere and clouds; and the author has endeavoured to imitate Nature's reflector in a way suitable to our imperfect means and conditions, and to the circumstances of each individual case.

\section{THE VOYAGE OF THE "CHALLENGER." "}

\section{II.}

THE plan adopted in the narrative of the cruise gives the reader a good idea of the course of the voyage, the nature of the researches, carried on, and the manner in which these researches have been followed up by the more detailed studies of the experts into whose hands the collections were afterwards placed. But it is necessarily desultory. We are led from station to station, from chemical to biological work, from physics to ethnology, from deep-sea temperatures to the anatomy of sea-slugs, with a rapidity and suddenness that are a little bewildering. Still, the general impression of the far-reaching aims of the expedition, of the skill and completeness with which the work was done, and of the enormous mass of new material obtained, is no doubt deepened by the difficulty or impossibility which the narrators have obviously experienced in giving within the brief compass of their chapters anything like a comprehensive digest of what the Challenger voyage accomplished in regard to the problems

\pm This shows a loss of $4^{*} 35$ per cent. owing to absorption by mirror.

2 "Report on the Scientific Results of the Voyage of H.M.S. Challenger during the years $1873-76 . "$ Prepared under the direction of the late Sir C. Wyville Thomson, and now of John Murray. "Narrative," vol. I., x885.
Continued from p. 20\%. of the great deep. The reader must resign himself to be carried along as the naturalists of the expedition themselves were, and to listen to their story of what they saw and found.

In our notice of last week we left the Challenger at the Cape of Good Hope. From that station she strikes out boldly into the Southern Ocean, giving us glimpses of the Prince Edward and Marion Islands, with their proofs of recent volcanic action, the Crozet Islands and Kerguelen. In this part of the voyage the trawlings are extraordin-

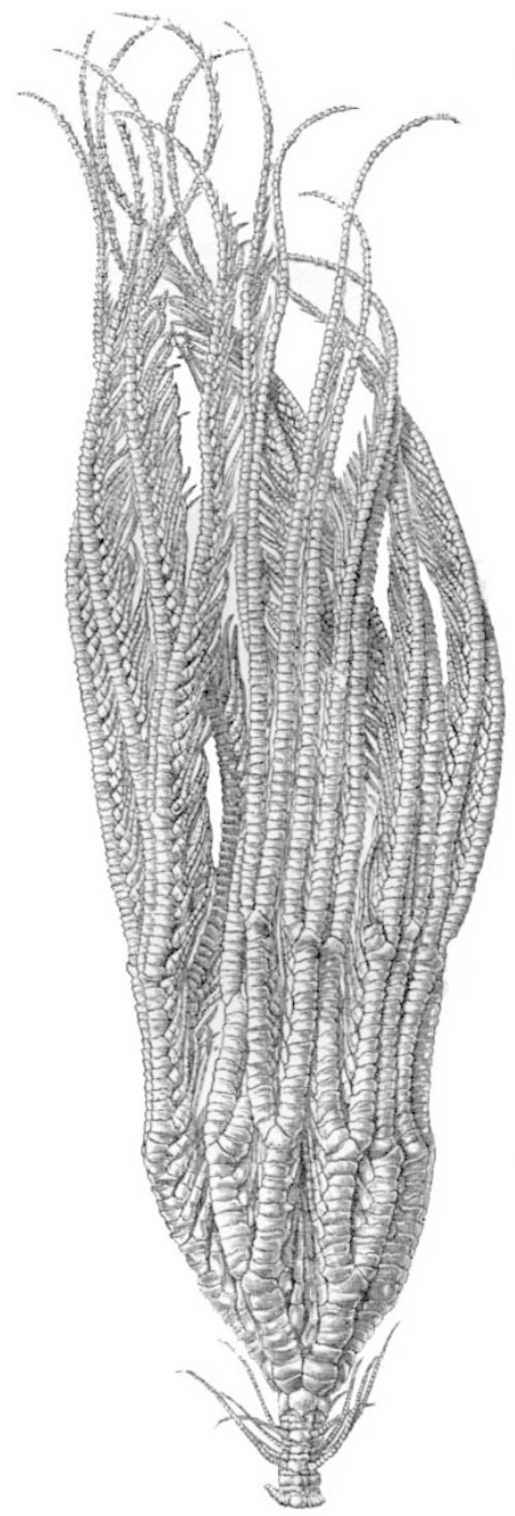

FIG. 4. -Metacrinus Wyvillii, P. H. Carpenter.

arily rich, between one and two hundred animals coming up at each haul, representing nearly all the marine groups, and, with few exceptions, belonging to genera and species discovered now for the first time. Among the more interesting forms of life are various crinoids, the mention of which leads to a summary from Dr. P. A. Carpenter and Prof. L. von Graff of their Reports upon the additions to our knowledge of the recent crinoids made by the expedition Fig. 4). The figures of the living Pentacrinus remind the 